\title{
Efficiently engineered cell sheet using a complex of polyethylenimine-alginate nanocomposites plus bone morphogenetic protein 2 gene to promote new bone formation
}

\author{
This article was published in the following Dove Press journal: \\ International Journal of Nanomedicine \\ 7 May 2014 \\ Number of times this article has been viewed
}

Han Jin'
Kai Zhang
Chunyan Qiao'
Anliang Yuan'
Daowei Li'
Liang Zhao'
Ce Shi'
Xiaowei Xu'
Shilei Ni'
Changyu Zheng
Xiaohua Liu ${ }^{4}$
Bai Yang ${ }^{2}$
Hongchen Sun'
'Department of Pathology, School
of Stomatology, Jilin University,
Changchun, People's Republic of
China; ${ }^{2 S t a t e ~ K e y ~ L a b o r a t o r y ~ o f ~}$
Supramolecular Structure and
Materials, College of Chemistry,
Jilin University, Changchun, People's
Republic of China; ${ }^{3}$ Molecular
Physiology and Therapeutics Branch,
National Institute of Dental and
Craniofacial Research, National
Institutes of Health, Bethesda, MD,
USA; ${ }^{4}$ Department of Biomedical
Sciences, Texas A\&M University
Baylor College of Dentistry, Dallas,
TX, UsA

Correspondence: Hongchen Sun Department of Pathology, School of Stomatology, Jilin University, I500 Qinghua Road, Changchun I3002I, People's Republic of China

Tel +8643 I 88796012

Fax+8643I 88975348

Email hcsun@jlu.edu.cn

\begin{abstract}
Regeneration of large bone defects is a common clinical problem. Recently, stem cell sheet has been an emerging strategy in bone tissue engineering. To enhance the osteogenic potential of stem cell sheet, we fabricated bone morphogenetic protein $2(B M P-2)$ gene-engineered cell sheet using a complex of polyethylenimine-alginate (PEI-al) nanocomposites plus human BMP-2 complementary(c)DNA plasmid, and studied its osteogenesis in vitro and in vivo. PEI-al nanocomposites carrying $B M P-2$ gene could efficiently transfect bone marrow mesenchymal stem cells. The cell sheet was made by culturing the cells in medium containing vitamin $\mathrm{C}$ for 10 days. Assays on the cell culture showed that the genetically engineered cells released the BMP-2 for at least 14 days. The expression of osteogenesis-related gene was increased, which demonstrated that released BMP-2 could effectively induce the cell sheet osteogenic differentiation in vitro. To further test the osteogenic potential of the cell sheet in vivo, enhanced green fluorescent protein or BMP-2-producing cell sheets were treated on the cranial bone defects. The results indicated that the BMP-2-producing cell sheet group was more efficient than other groups in promoting bone formation in the defect area. Our results suggested that PEI-al nanocomposites efficiently deliver the $B M P-2$ gene to bone marrow mesenchymal stem cells and that $B M P-2$ gene-engineered cell sheet is an effective way for promoting bone regeneration.
\end{abstract}

Keywords: bone regeneration, bone tissue engineering, nanocomposites, cell sheet, bone morphogenetic protein 2

\section{Introduction}

Bone loss caused by congenital defects, traumatic injury, cancer, reconstructive surgery, or periodontal disease has aroused widespread concern all over the world. Regeneration of bone remains an important clinical challenge because the regeneration potential of human bone appears to be limited. ${ }^{1}$ The obstacles of current bone substitutes include the limited amounts of donor bone, the bone resorption of autografts, the risk of disease transmission and graft rejection of allografts, and the shortage of osteoinductive property for synthetic grafts. ${ }^{2,3}$ Bone tissue engineering (BTE) attempts to solve the referred problems mentioned. Recently, stem cell- and gene-based therapy has been applied in BTE and achieved some good clinical results. ${ }^{4-6}$

Traditional BTE involves three-dimensional biodegradable scaffolds, stem cells, and osteoinductive growth factors. It is a complex and dynamic process to form a continuous construct via the cells' adhesion, proliferation, differentiation, and extracellular matrix (ECM) deposition on a scaffold. ${ }^{7}$ However, the scaffolds still face the problem of 
biocompatibility, mechanical properties, and bioresorbability, which are not adaptable to the properties of natural bone. ${ }^{7}$ So a cell sheet without scaffold was invented. It is made by culturing the cells on a temperature-responsive culture dish or adding some exogenous factors in the period of cell culture to form a sheet, then lifting the cell sheet using a scraper. ${ }^{8-10}$ The cell sheet made by these methods not only maintains the connections between cells and ECM but also makes it easy to transplant for bone defect treatment. ${ }^{10,11}$ Wei et $\mathrm{al}^{12}$ developed a method by which vitamin $\mathrm{C}(\mathrm{Vc})$ alone was used to induce the cell sheet formation, which provided an easy and practical tissue engineering approach. In this study, we obtained a Vc-based bone marrow mesenchymal stem cell (BMSC) sheet, which was modified by bone morphogenetic protein-2 (BMP-2) gene.

Bone morphogenetic proteins (BMPs) are well known as osteoinductive growth factors that play an important role in the bone regeneration process. Since the discovery of BMPs by Urist $^{13}$ in 1965 , many studies have shown that these proteins are capable of inducing the osteogenic differentiation of mesenchymal cells and ectopic de novo bone formation and healing bone defects of critical size. ${ }^{13-15}$ BMPs are commercially available in recombinant (rh) forms, and encouraging results have been achieved with rhBMPs in clinical studies of nonunion bone defects, open tibial fractures, and spinal fusion. ${ }^{16-18}$ However, the problems of high cost, short protein half-life, requirement of a large amount of rhBMP, and the need for repeated applications are obstacles that still have to be overcome. ${ }^{19} B M P-2$ gene transfection has been investigated for bone regeneration as an alternative to BMP-2 protein therapy. ${ }^{4,5,20}$ So far, the main approach to gene delivery in gene therapy is viral vector systems, due to their relatively high transfection efficiency. However, the use of nonviral gene vectors has emerged as a viable alternative to viral-based gene vectors, because they overcome the limitation of viral vectors, such as immune response, oncogenicity, and difficulty in large-scale production and purification. ${ }^{4,21}$

Patnaik et $\mathrm{al}^{22}$ prepared a series of polyethylenimine (PEI) (linear $750 \mathrm{kDa}$ and branched $25 \mathrm{kDa}$ )-alginate (PEI-al) nanocomposites as a kind of novel nonviral gene vector. PEI-al nanocomposites exhibit higher transfection efficiency and lower cytotoxicity than those of commercial transfection reagents. We chose these nanocomposites as the transgene vector of our study. In this study, we utilize PEI-al nanocomposites as a BMP-2 gene carrier to transfect BMSCs and fabricate a BMP-2-producing cell sheet, which provides an effective method of promoting bone healing in bone defect.
Specifically, this study involves 1) the preparation of PEI-al nanocomposites and PEI-al/BMP-2 plasmid (pBMP-2) complexes, 2) the development of BMP-2-producing BMSC sheet by transfection with PEI-al/pBMP-2, 3) investigating the PEI-al/pBMP-2 complexes on osteogenic differentiation of BMSCs in vitro, and 4) determining the effect of the BMP-2-producing cell sheet on promoting bone formation in craniofacial bone defect in vivo.

\section{Materials and methods Synthesis of PEI-al nanocomposites and PEI-al/DNA complexes}

In order to produce highly efficient PEI-al nanocomposites, alginate and PEI were fabricated using a procedure developed by Patnaik et al. ${ }^{22}$

\section{Purification of alginic acid}

First of all, alginic acid was purified from commercially available sodium alginate (Sigma-Aldrich, St Louis, MO, USA). Activated charcoal granules $(0.1 \mathrm{~g} / \mathrm{g}$ of sodium alginate) were added to $0.1 \%$ sodium alginate solution and heated at $70^{\circ} \mathrm{C}$ while stirring for 30 minutes. The solution was filtered through a $0.22 \mu \mathrm{m}$ membrane and $0.1 \mathrm{M}$ hydrochloric acid was added to adjust the $\mathrm{pH}$ of filtrate to $\mathrm{pH}$ 4.0. Then, the solution was refiltered and concentrated under a rotary evaporator (SENCO, Shanghai, People's Republic of China) and dried to obtain alginic acid as a transparent film.

\section{Preparation of $\mathrm{PEI}-\mathrm{al}$ nanocomposites and PEI-al/pBMP-2 complexes}

The preparation of PEI-al nanocomposites was performed by electrostatic interactions between PEI (molecular weight $=25,000$ Da, bPEI 25 k [branched PEI 25 kDa, SigmaAldrich]) and alginic acid. Briefly, $0.9 \mathrm{mg}$ alginic acid was dissolved in $90 \mathrm{~mL}$ deionized water after being heated at $90^{\circ} \mathrm{C}$ for 1 hour. After that, alginic acid solution was added dropwise into a preheated $\left(90^{\circ} \mathrm{C}\right)$ solution of PEI $(5 \mathrm{mg}$ dissolved in $500 \mathrm{~mL}$ of water) with continuous stirring, and the temperature was maintained at $90^{\circ} \mathrm{C}$ for 4 hours. Then, the solution was concentrated to $20 \mathrm{~mL}$ on a rotary evaporator (SENCO) and filtered through a $0.22 \mu \mathrm{m}$ sterile membrane filter to obtain a sterile solution of PEI-al nanocomposites.

PEI-al/pBMP-2 complexes were prepared by mixing PEI-al nanocomposites and human BMP-2 cDNA plasmid at different weight ratios $(\mathrm{w} / \mathrm{w})$ and incubated for 30 minutes at room temperature. 


\section{Characterization of PEI-al}

nanocomposites and PEI-al/DNA

\section{complexes}

\section{Physicochemical properties of PEl-al nanocomposites and PEI-al/DNA complexes}

The size and zeta potential of the PEI-al nanocomposites and their DNA complexes were assessed by dynamic light scattering (Malvern Zetasizer Nano Z; Malvern Instruments, Malvern, UK). To do this, the samples were measured in water and placed into an analyzer chamber. The size was assessed by three cycles, and zeta potential was performed by three repeated cycles with 100 runs each.

The morphology of the PEI-al nanocomposites and their DNA complexes was also studied by field emission scanning electron microscopy (SEM; FE-SEM 6700F; JEOL, Tokyo, Japan). Samples of complexes were dropped on silicon pieces and mounted on metal stubs, subsequently, they were coated with platinum under vacuum, then examined by SEM. Transmission electron microscopy (TEM; Tecnai G2 F20 S-Twin; FEI, Hillsboro, OR, USA) was also used to observe the morphology of the PEI-al nanocomposites and their DNA complexes. Samples were stained with phosphotungstic acid, dropped on copper grids dried at room temperature, and observed by TEM.

PEI-al nanocomposites, PEI, and alginate solution were dropped on the calcium fluoride sheets and dried under an infrared lamp (250 W, Philips, Amsterdam, the Netherlands), and then their Fourier transform infrared (FTIR) spectra were characterized by an FTIR spectrophotometer (Nicolet Avatar 360; Thermo Electron Corporation, Waltham, MA, USA) in a 4,000-1,000 $\mathrm{cm}^{-1}$ wavenumber range.

\section{Agarose gel retardation assay}

The PEI-al/pBMP-2 complex solution was prepared by premixing PEI-al solution with pBMP-2 (0.4 $\mu \mathrm{g}$ BMP-2 plasmid) at different $\mathrm{w} / \mathrm{w}$ ratios ranging from $0.5: 1$ to $4: 1$, and diluted by deionized water to the total volume of $9 \mu \mathrm{L}$. Next, $1 \mu \mathrm{L}$ of loading buffer $(10 \times)$ was added into each sample, and then the mixtures were checked by electrophoresis using $1.0 \%$ agarose gel.

\section{In vitro study}

\section{Cell culture}

BMSCs were obtained from the bone marrow of male Wistar rats (80-100 g) by whole bone marrow adherent culture methods. They were cultured in Dulbecco's Modified Eagle's Medium (DMEM; Life Technologies,
Carlsbad, CA, USA), supplemented with 10\% fetal bovine serum (FBS, Life Technologies), $100 \mathrm{U} / \mathrm{mL}$ penicillin, and $100 \mu \mathrm{g} / \mathrm{mL}$ streptomycin (1\% PS, Life Technologies). Cells were cultured in $5 \%$ carbon dioxide atmosphere at $37^{\circ} \mathrm{C}$.

\section{Transfection procedure}

The cells were seeded 24 hours prior to transfection on sixwell plates at a density of $2 \times 10^{5}$ cells/well in $2 \mathrm{~mL}$ of DMEM supplemented with $10 \%$ FBS and 1\% PS. Before transfection, the culture medium was replaced with $1 \mathrm{~mL}$ of serum-free DMEM, previously mixed with PEI-al/pBMP-2 and PEI-al/ enhanced green fluorescent protein cDNA plasmid ( $p E G F P$ ) complex at different $\mathrm{w} / \mathrm{w}$ ratios of nanocomposites and plasmid (p)DNA. The amount of plasmid was constant at $2 \mu \mathrm{g}$. After incubation for 4 hours, the transfection medium was removed, and complete culture medium was then added. Cells were incubated at $37^{\circ} \mathrm{C}$ to allow expression of the transfected gene.

To demonstrate transfection efficiency, flow cytometry was performed on PEI-al/pEGFP and PEI/pEGFP (pEGFP was $2 \mu \mathrm{g}$ per well, PEI-al/pEGFP with the $\mathrm{w} / \mathrm{w}$ ratios of $2: 1$ and $3: 1, \mathrm{PEI} / \mathrm{pEGFP}$ was $1: 1$ ) transfected BMSCs. Forty-eight hours after transfection, cells were washed twice with PBS and resuspended in $500 \mu \mathrm{L}$ of PBS. The transfection efficiency of the suspended cell samples was then analyzed by flow cytometry (BD Biosciences, San Jose, CA, USA).

\section{Fabrication of gene-engineered cell sheet}

The BMSCs were seeded 24 hours prior to transfection on six-well plates at a density of $2 \times 10^{5}$ cells/well in $2 \mathrm{~mL}$ of DMEM supplemented with 10\% FBS and 1\% PS. Cells were transfected by PEI-al/pBMP-2 and PEI-al/pEGFP (the w/w ratio was $3: 1$ ). The transfection procedure was the same as previously mentioned. The cells were cultured in medium containing Vc (20 $\mu \mathrm{g} / \mathrm{mL}$, Sigma-Aldrich) for 10 days until cell sheet formation, and the cell sheet was lifted using a scraper (Figure 1B). ${ }^{12}$ There were two kinds of cell sheets: BMP-2 gene-modified BMSC cell sheet (BMP/CS) and EGFP gene-modified BMSC cell sheet (EGFP/CS).

\section{Cell viability}

An evaluation of cell viability at 48 hours post-transfection using PEI-al/pBMP-2 and PEI/pBMP-2 complexes (pBMP-2 was $0.2 \mu \mathrm{g}$ per well, PEI-al/pBMP-2 and PEI/pBMP-2 with different $w / w$ ratios of $0,0.5: 1,1: 1,2: 1$, and $3: 1$ ) was performed with a 3-(4,5-dimethylthiazol-2-yl)-2,5-diphenyltetrazolium bromide (MTT) cell growth assay (AMRESCO, Solon, $\mathrm{OH}, \mathrm{USA})$. BMSCs $\left(1 \times 10^{4}\right)$ received $200 \mu \mathrm{L}$ of medium 

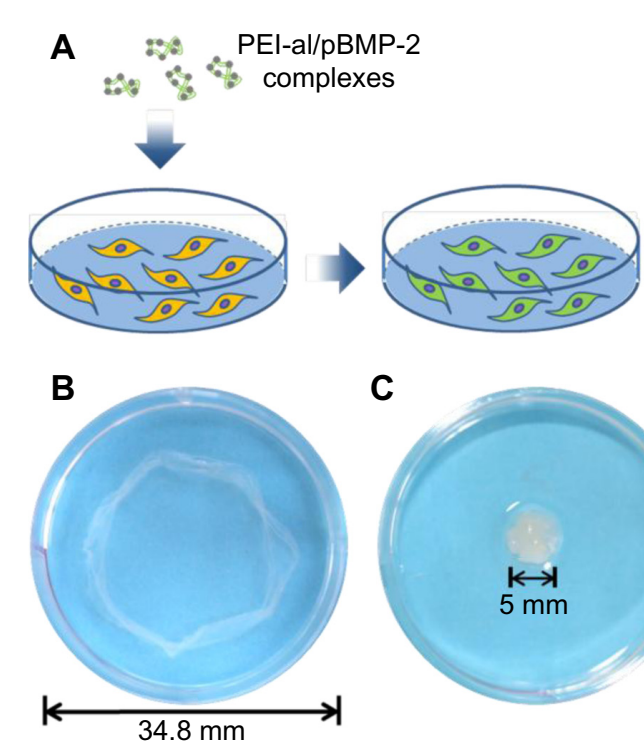

C

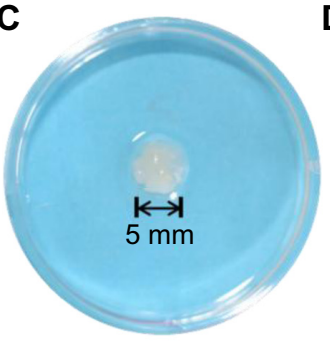

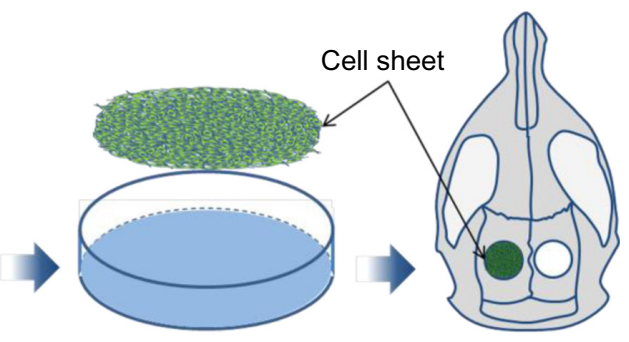

D

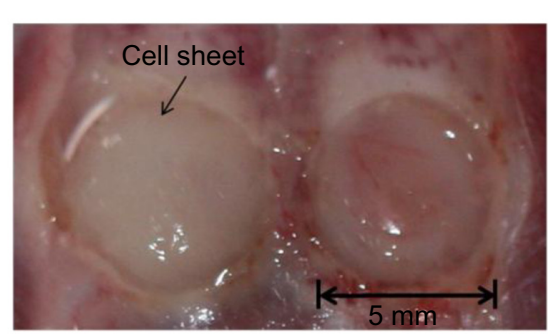

Figure I Fabrication of BMP-2-producing cell sheet and surgical schematic. (A) A schematic presentation of the fabrication procedure for the cell sheet and the surgical procedure. (B) Cultured BMSCs were lifted as a cell sheet using a scraper. (C) The cell sheet was folded to adapt the shape of the calvarial defect. (D) Two 5 mm diameter defects were prepared at the calvarial area of a rat, and the cell sheet was transplanted into the defect.

Abbreviations: BMSCs, bone marrow mesenchymal stem cells; PEI-al/pBMP-2, polyethylenimine-alginate/plasmid of bone morphogenetic protein 2; BMP-2, bone morphogenetic protein 2 .

per well containing $20 \mu \mathrm{L}$ of $5 \mathrm{mg} / \mathrm{mL}$ MTT solution and were incubated for an additional 4 hours at $37^{\circ} \mathrm{C}$. Then, the MTT-containing medium was replaced by $150 \mu \mathrm{L}$ dimethyl sulfoxide to dissolve the formazan crystals. Absorbance was measured at $490 \mathrm{~nm}$ using a microplate reader (RT-6000; Lei Du Life Science and Technology Co, Shenzhen, People's Republic of China) with the percent cell viability of the control (nontransfected) cells taken as $100 \%$.

\section{Enzyme-linked immunosorbent assay}

BMSCs were transfected by PEI-al/pBMP-2 as per the procedure described previously, and the cell culture medium was changed every 2 days post-transfection. The cell culture medium on days $2,4,8$, and 14 was collected for enzymelinked immunosorbent assay (ELISA) analysis. Human BMP-2 concentration was determined using a BMP-2 ELISA kit (R\&D Systems, Minneapolis, MN, USA).

\section{RNA extraction and quantitative real-time polymerase chain reaction}

BMSCs were transfected by PEI-al/pBMP-2 as per the procedure described previously and cultured in Vc-containing medium for 3, 7, and 14 days. The cells transfected by PEI-al/ pEGFP were used as a control. At each time point, cells were digested by trypsin and total RNA of cells was isolated using a Qiagen RNeasy mini purification kit (Qiagen, Valencia, CA, USA) according to the manufacturer's instructions. One microgram of RNA was reverse transcribed using iScript ${ }^{\mathrm{TM}}$ cDNA synthesis kit (Takara Bio, Tokyo, Japan). The quantitative real-time polymerase chain reaction (qPCR) was performed by MxPro Mx3005P real-time PCR detection system (Agilent Technologies, Santa Clara, CA, USA) using SYBR-Green Premix Ex Taq (Takara Bio) $(n=3)$ according to the manufacturer's instructions. The conditions of real-time PCR were as follows: 40 cycles at $94^{\circ} \mathrm{C}$ for 5 seconds and $60^{\circ} \mathrm{C}$ for 34 seconds. A dissociation stage was added to the end of the amplification procedure. There was no nonspecific amplification determined by the dissociation curve. B-actin was used as internal control. The primer sequences used for this analysis were as follows: $\beta$-actin, 5'-GGAGATTACTGCCCTGGCTCCTA-3'/ 5'-GACTCATCGTACTCCTGCTTGCTG-3'; type I collagen (COLL I), 5'-GACATGTTCAGCTTTGTGGACCTC-3'/ 5' - A G G G A C C C T TA G G C C AT T G T G TA - 3'; Runt-related transcription factor 2 (RUNX2), 5' - C A T G G C C G G G A A T G A T GA G - 3'/ 5' - TGTGAAGACCGTTATGGTCAAAGTG-3'; SP 7, 5' - C AT C C AT G C A G GC AT C T C A - 3'। 5'-CTGCCCACCACCTAACCAA-3'; alkaline phosphatase (ALP), 5'-CATCGCCTATCAGCTAATGCACA-3'/ 5'-ATGAGGTCCAGGCCATCCAG-3'. Primers were synthesized commercially (Takara Bio, Dalian, People's Republic of China).

\section{In vivo animal experiment \\ Animals}

The animal experiments used for this study were approved by the Animal Care and Use Committee of Jilin University, Changchun, People's Republic of China. Twelve male Wistar 
rats (average weight $350 \mathrm{~g}$ ) were used. The animals were maintained at a temperature of $22^{\circ} \mathrm{C}$ in a $12 / 12$-hour light/ dark cycle and fed with a standard laboratory diet and water. A total of 24 calvarial defects ( $5 \mathrm{~mm}$ diameter) were randomly divided into three groups: the BMP/CS treatment group, the $\mathrm{EGFP} / \mathrm{CS}$ treatment group, and the control (no defect treatment) group.

\section{Surgical procedure}

The animals were anesthetized with ketamine $(60 \mathrm{mg} / \mathrm{kg})$ and xylazine $(8 \mathrm{mg} / \mathrm{kg})$. The surgical area was shaved and the skin was sterilized with $75 \%$ ethanol. A $20 \mathrm{~mm}$-long incision was made in the scalp along the sagittal suture, and then the calvarial area was exposed. Two $5 \mathrm{~mm}$ diameter defects were prepared with a trephine bur (3i Implant Innovation, Palm Beach Gardens, FL, USA) on each side of the midsagittal suture at the dorsal part of the parietal region. The cell sheets of EGFP/CS and BMP/CS were folded to fit the shape of the defects (Figure 1). Then, the defects were treated with cell sheets, the groups were divided as described previously, and the skin closure was accomplished using 3-0 nylon suture. The day of surgery was assigned as day 0.

\section{Analysis of in vivo experiment results}

Four and 8 weeks later, the rats were killed by perfusion fixation with $4 \%$ paraformaldehyde solution. The relevant part of the skull was removed and fixed in 4\% paraformaldehyde solution. The degree of bone formation was examined using microcomputed tomography (micro-CT) (micro-CT 35; Scanco Medical AG, Bassersdorf, Switzerland), and the bone formation area was calculated by Image-Pro Plus software (Image-Pro Plus 6.0; Media Cybernetics, Rockville, MD, USA).

After visualization of the bone healing by micro-CT scanning, the samples were prepared for histologic analysis. They were immersed in 10\% ethylene diamine tetraacetic acid for decalcification, and the fresh solution was changed every week. After decalcification, samples were embedded in paraffin and tissues were stained with hematoxylin and eosin (H and $\mathrm{E})$.

\section{Evaluation of toxicity of secreted BMP-2 protein in vivo}

To further evaluate whether the secreted BMP-2 protein can cause toxicity in vivo, blood, liver, spleen, and kidney samples were collected from the control group and the treated group. Eighteen male Wistar rats (average weight $350 \mathrm{~g}$ ) were divided into two groups: the cell sheet (without gene modification) (CS) group as a control group and the BMP/CS treatment group. A single defect was prepared on one side of the midsagittal suture at the dorsal part of the parietal region, then the cell sheet from the control group or the BMP-treated group was transplanted to the defect. The surgical procedure was the same as described previously. At 1, 3, and 7 days after surgery, blood samples and serum samples were collected. Liver, spleen, and kidney samples were obtained on day 7 after surgery. The hematological parameters (white blood cell number, red blood cell number, hemoglobin concentration, and platelets) were measured by a hematology analyzer (MEK7222K; Nihon Kohden, Tokyo, Japan). Serum biochemical parameters of total protein, alanine aminotransferase, aspartate aminotransferase, blood urea nitrogen, and creatinine were determined using commercial kits (Roche Diagnostics, Mannheim, Germany). Liver, spleen, and kidney samples were prepared for histologic analysis. They were fixed in 4\% paraformaldehyde solution, then embedded in paraffin, and tissues were stained with $\mathrm{H}$ and $\mathrm{E}$.

\section{Statistical analysis}

Results are expressed as mean \pm standard deviation. One-way analysis of variance followed by Tukey's post hoc analysis was used to test for statistical significance. A $P$-value $<0.05$ was considered to be significantly different in all cases.

\section{Results \\ Physicochemical characterization of the PEI-al nanocomposites and $\mathrm{PEI}-\mathrm{al} / \mathrm{pDNA}$ complexes}

Table 1 shows the average size and zeta potential of PEI-al nanocomposites and PEI-al/pBMP-2 complexes. Dynamic light scattering results show that the mean hydrodynamic diameter of PEI-al nanocomposites and PEI-al/pBMP-2 complexes were approximately $73.8 \mathrm{~nm}$ and $149.6 \mathrm{~nm}$, respectively (Table 1). SEM images show that the morphology of PEI-al nanocomposites was spherical nanoparticles. After binding with plasmid DNA, there was aggregation (Figure 2A and B). TEM images of PEI-al nanocomposites and their DNA complexes show similar morphology to their SEM images (Figure 2C and D).

Table I Physical characteristics of PEI-al nanocomposites, BMP-2 plasmid, and PEI-al/pBMP-2 complexes

\begin{tabular}{lcl}
\hline Sample & $\begin{array}{l}\text { Average particle } \\
\text { size }(\mathbf{n m})\end{array}$ & $\begin{array}{l}\text { Zeta potential } \\
(\mathbf{m V})\end{array}$ \\
\hline PEI-al & $73.8 \pm 5.1$ & $+19.9 \pm 1 . I$ \\
BMP-2 plasmid & $1,097.0 \pm 33.8$ & $-36.4 \pm 2.2$ \\
PEI-al/pBMP-2 & $\mid 49.6 \pm 13.0$ & $+18.8 \pm 0.8$ \\
\hline
\end{tabular}

Notes: Data are expressed as mean \pm standard deviation.

Abbreviations: $\mathrm{PEI}-\mathrm{al}$, polyethylenimine-alginate; BMP-2, bone morphogenetic protein 2; pBMP-2, plasmid of bone morphogenetic protein 2. 
Zeta potentials for the PEI-al nanocomposites and PEI-al/ pBMP-2 were $19.9 \mathrm{mV}$ and $18.8 \mathrm{mV}$, respectively (Table 1).

The molecular structure of PEI-al nanocomposites was characterized by FTIR spectra. Figure 2E shows the characteristic peaks of PEI at $3,300 \mathrm{~cm}^{-1}(\mathrm{~N}-\mathrm{H}$ stretching vibration); $1,660 \mathrm{~cm}^{-1}$, and $1,565 \mathrm{~cm}^{-1}$ (amine scissoring bending vibration); $1,466 \mathrm{~cm}^{-1}$ (C-H stretching vibration); and $1,121 \mathrm{~cm}^{-1}$ (C-N stretching vibration), and the characteristic peaks of alginate were seen at $1,620 \mathrm{~cm}^{-1}(\mathrm{C}=\mathrm{O}$ stretching vibration) and $1,423 \mathrm{~cm}^{-1}$ (carboxyl stretching vibration). In the PEI-al nanocomposites spectrum the signals of PEI and alginate at $3,300 \mathrm{~cm}^{-1}, 1,660 \mathrm{~cm}^{-1}, 1,565 \mathrm{~cm}^{-1}, 1,121 \mathrm{~cm}^{-1}$, and $1,423 \mathrm{~cm}^{-1}$ disappeared and were replaced by new absorption peaks at $1,652 \mathrm{~cm}^{-1}$ (the peak of $\mathrm{C}=\mathrm{O}$ at $1,620 \mathrm{~cm}^{-1}$ was shifted to a higher wave) and $1,521 \mathrm{~cm}^{-1}\left(-\mathrm{NH}_{3}^{+}\right)$. The peak of PEI at $1,466 \mathrm{~cm}^{-1}$ was also observed in the PEI-al nanocomposites spectrum. By comparing the absorption peaks of PEI, alginate, and PEI-al nanocomposites, it indicates the formation of PEI-al nanocomposites as a result of ionic interaction between the amino band $\left(-\mathrm{NH}_{2}\right.$ and $\left.-\mathrm{NH}-\right)$ of PEI and the carbonyl band $(-\mathrm{COOH})$ of alginate.

The interactions between PEI-al nanocomposites and BMP-2 plasmid at different $\mathrm{w} / \mathrm{w}$ ratios were investigated by agarose gel electrophoresis. As is shown in Figure 2F, the migration of BMP-2 plasmid was completely retarded when the $\mathrm{w} / \mathrm{w}$ ratio was over $1.5: 1$. It suggests the formation of
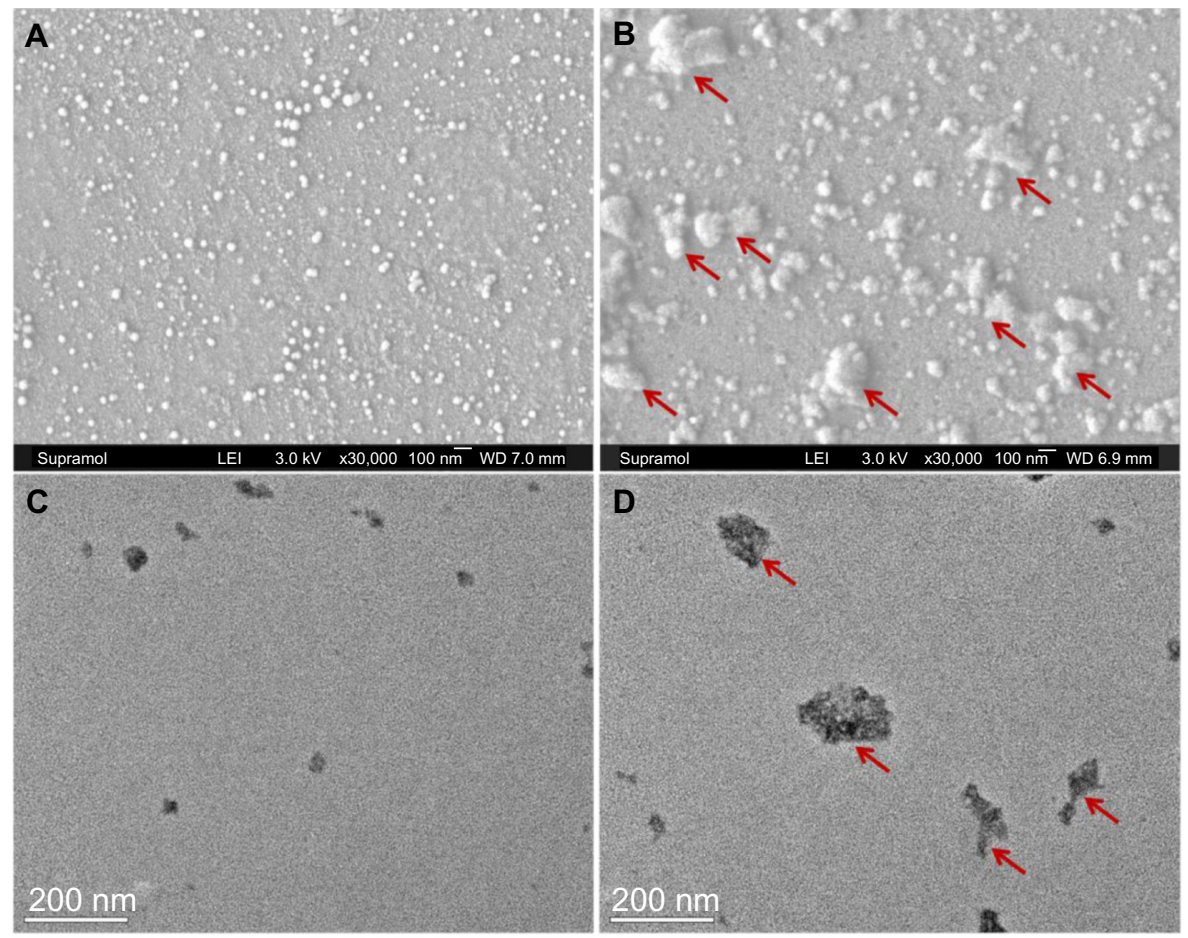

E

F
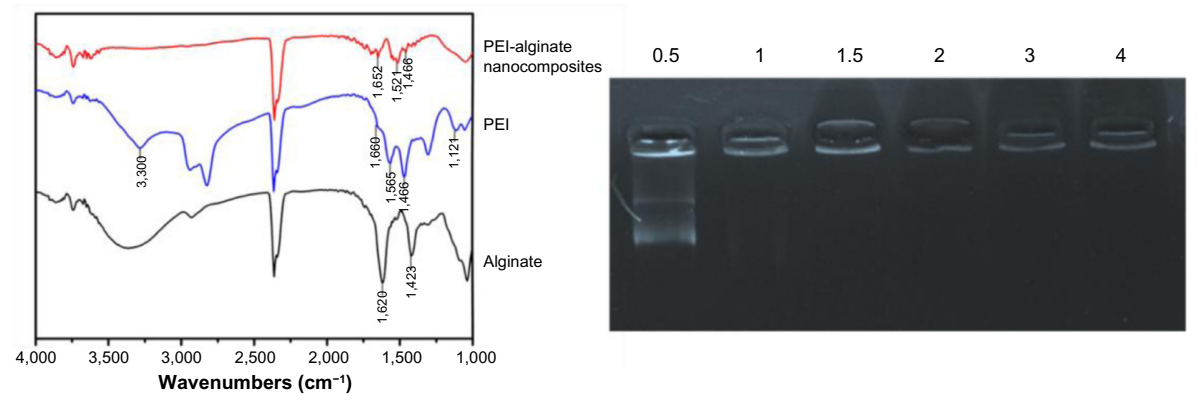

Figure 2 Physicochemical characterization of the PEI-al nanocomposites and PEI-al/pBMP-2 complexes. (A) SEM images of PEI-al nanocomposites. (B) SEM images of PEI-al/ pBMP-2 complexes. Red arrows indicate PEI-al/pBMP-2 complexes. (C) TEM images of PEI-al nanocomposites. (D) TEM images of PEI-al/pBMP-2 complexes. Red arrows indicate PEI-al/pBMP-2 complexes. (E) FTIR spectra of PEI-al nanocomposites, PEl, and alginate. (F) Agarose gel electrophoresis retardation assay of PEI-al/pBMP-2 at various w/w ratios of $0.5: 1$, I:I, I.5:I, 2:I, 3:I, and 4:I.

Abbreviations: FTIR, Fourier transform infrared; PEI-al/pBMP-2, polyethylenimine-alginate/plasmid of bone morphogenetic protein 2; SEM, scanning electron microscopy; TEM, transmission electron microscopy; w/w ratios, weight ratios; $\mathrm{PEI-al,} \mathrm{polyethylenimine-alginate;} \mathrm{PEl,} \mathrm{polyethylenimine.}$ 
neutral or positively charged complexes between PEI-al and BMP-2 plasmid when the $\mathrm{w} / \mathrm{w}$ ratio reached 1.5:1.

\section{Characteristics of PEI-al/pEGFP or $\mathrm{PEI}-\mathrm{al} / \mathrm{pBMP}-2$ on BMSCs in vitro}

To evaluate the transfection efficiency of PEI-al nanocomposites, BMSCs were transfected with PEI-al/pEGFP. The results of flow cytometry showed that the transfection efficiency of PEI-al/pEGFP on BMSCs was $8.13 \%$ and $11.93 \%$ with a $\mathrm{w} / \mathrm{w}$ ratio of PEI-al nanocomposites and EGFP plasmid of 2:1 and 3:1, respectively, whereas that of PEI $(\mathrm{w} / \mathrm{w}=1: 1)$ was $4.78 \%$ (Figure $3 \mathrm{~A}$ ).

To determine the cytotoxicity of PEI-al nanocomposites, BMSCs were transfected with PEI-al/pBMP-2 and PEI/pBMP-2 complexes. After 48 hours post-transfection, the cytotoxicity was examined by MTT assay. The results showed that there was almost no cytotoxicity of PEI-al/pBMP-2 at a w/w ratio of less than 2:1, but there was significant toxicity of PEI/pBMP-2 with a w/w ratio of $1: 1$. And PEI-al/pBMP-2 complexes were significantly less toxic than PEI/pBMP-2 complexes when their $\mathrm{w} / \mathrm{w}$ ratios were higher than 1:1 (Figure 3B).

To quantify the secretion of BMP-2 protein, ELISA assay was performed on days 2, 4, 8, and 14 after transfection of PEI-al/pBMP-2 to BMSCs. Data from Figure 3C show that the transfected BMSCs secreted human BMP-2 protein for at least 14 days.
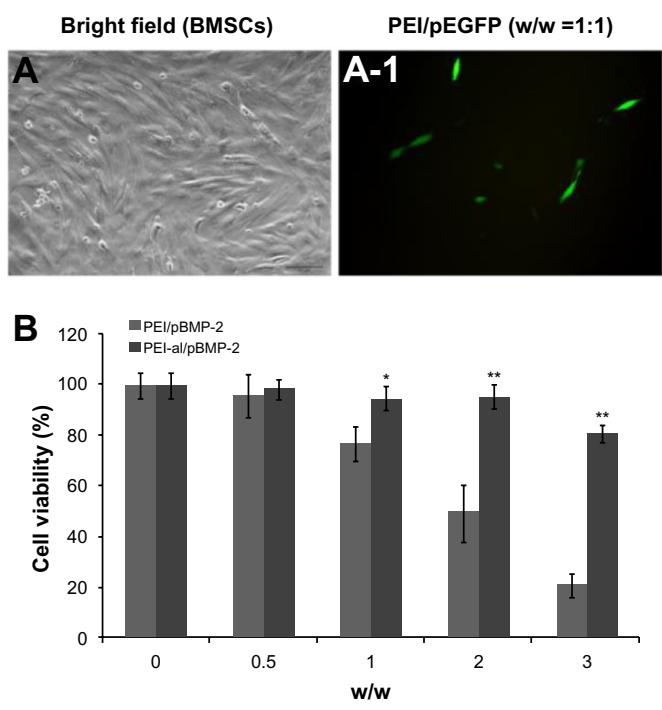

Effects of secreted BMP-2 protein on osteogenic differentiation of BMSCs

To evaluate how the secreted BMP-2 protein can induce osteogenic differentiation of BMSCs in vitro, gene expressions of COLL I, RUNX2, SP7, and $A L P$ were measured 3, 7, and 14 days after transfection of PEI-al/pBMP-2 and PEI-al/pEGFP to BMSCs. The result showed that gene expressions of $S P 7$ and $A L P$ in the PEI-al/pBMP-2 group were significantly increased on day 3 compared with those of the PEI-al/pEGFP group $(P<0.05)$. And each gene expression of PEI-al/pBMP-2 group was significantly higher than that of the PEI-al/pEGFP group on days 7 and $14(P<0.01)$ (Figure 4).

\section{Effects of BMP-2 protein-producing cell sheet on bone formation in vivo}

Bone formation after implanting BMP/CS or EGFP/CS to the defects at 4 and 8 weeks was observed using micro-CT and $\mathrm{H}$ and $\mathrm{E}$ histological staining. Micro-CT images showed that within 4 weeks the new bone formation was observed at the edge of the defect, and the BMP/CS group showed the most significant defect size reduction. At 8 weeks, the defect size in all groups was further decreased, especially the BMP/CS group (Figure 5A-F). Image-Pro Plus software was used to calculate the bone formation area at the defect

PEI-al/pEGFP (w/w =2:1) PEl-al/pEGFP (w/w =3:1)
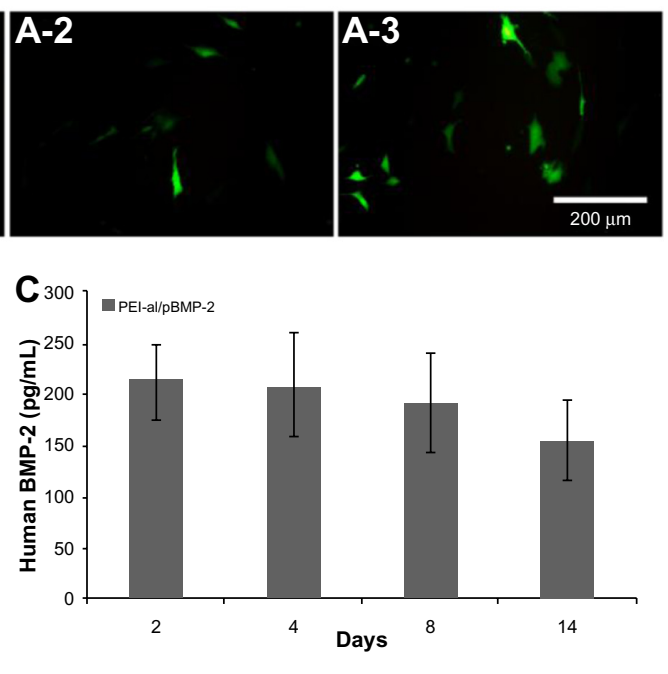

Figure 3 Evaluation of properties of PEI-al/pDNA on BMSCs in vitro. (A) Fluorescent microscopy images of BMSCs transfected with PEI/pEGFP and PEI-al/pEGFP complexes at different w/w ratios of nanocomposites/pEGFP. Bright field of BMSCs (A-I, A-2 and A-3) EGFP expression in BMSCs transfected by PEI/pEGFP (w/w $=1: 1$ ) and PEI-al/pEGFP $(\mathrm{w} / \mathrm{w}=2: \mathrm{I}$ and $3: \mathrm{I})$ complexes. Magnification of all images is $200 \times$. (B) Cell viability of PEI/pBMP-2 and PEI-al/pBMP-2 complexes at various w/w ratios of 0, 0.5:I, I:I, 2:I, and 3:I transfected to BMSCs. (C) Release of human BMP-2 protein from PEI-al/pBMP-2 (w/w =3:I) transfected BMSCs on days 2, 4, 8, and I4.

Notes: $* P<0.05 ; * * P<0.01$.

Abbreviations: BMSCs, bone marrow mesenchymal stem cells; pBMP-2, plasmid of bone morphogenetic protein 2; pEGFP, plasmid of enhanced green fluorescent protein; PEI-al/ pDNA, polyethylenimine-alginate/plasmid DNA; w/w, weight ratios; EGFP, enhanced green fluorescent protein; PEl, polyethylenimine; BMP-2, bone morphogenetic protein 2. 

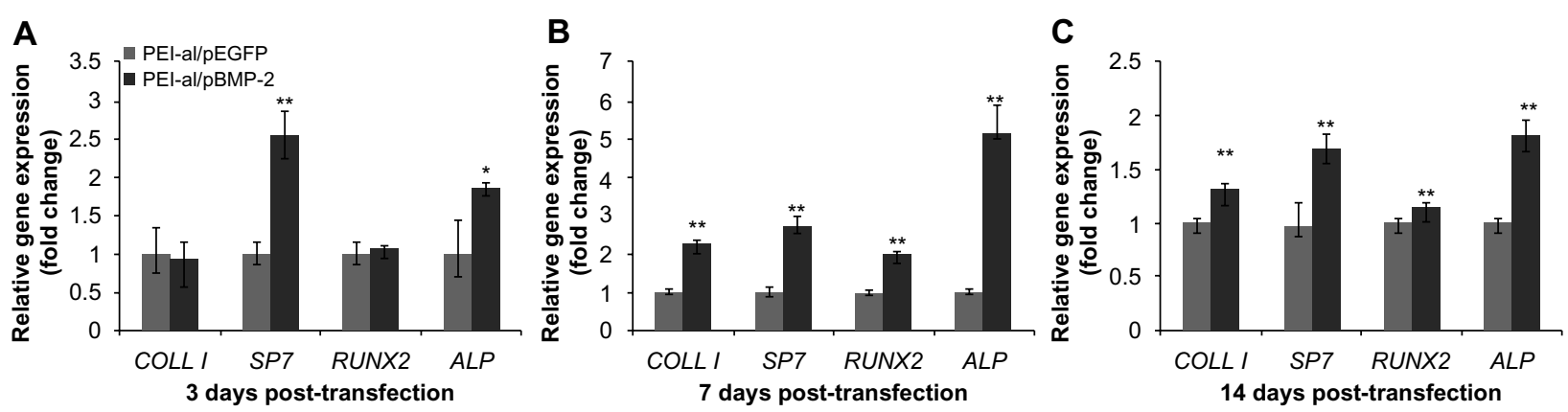

Figure 4 Expression of specific osteogenic genes (COLL I, SP7, RUNX2, ALP) of BMSCs evaluated by qPCR at 3, 7, and I4 days post-transfection with PEI-al/pEGFP and PEI-al/ pBMP-2 complexes. (A) 3 days post-transfection. (B) 7 days post-transfection. (C) 14 days post-transfection.

Notes: $* P<0.05 ; * * P<0.01$.

Abbreviations: ALP, alkaline phosphatase; COLL I, I type collagen; pBMP-2, plasmid of bone morphogenetic protein 2; PEI-al/pEGFP, polyethylenimine-alginate/plasmid of enhanced green fluorescent protein; qPCR, real-time quantitative polymerase chain reaction; RUNX2, runt-related transcription factor 2; SP7, Osterix; BMSCs, bone marrow mesenchymal stem cells.

site. The data from the analysis are presented in Figure 5G, which shows that there was significantly greater healing in the $\mathrm{BMP} / \mathrm{CS}$ group compared with the other groups. At 4 weeks, the bone formation area of the BMP/CS group was $48.3 \% \pm 6.3 \%$, which was significantly higher than the control group $(35.8 \% \pm 4.3 \%)(P<0.05)$. At 8 weeks, the bone formation area of the BMP/CS group had further increased to $57.9 \% \pm 6.5 \%$, which was significantly higher than that of the control group $(35.6 \% \pm 3.3 \%)(P<0.01)$ and the EGFP/ $\mathrm{CS}$ group $(48.1 \% \pm 2.1 \%)(P<0.05)$. $\mathrm{H}$ and $\mathrm{E}$ staining also showed that the new bone formation in the BMP/CS group was much more than that of the EGFP/CS group and the control group in the original defect margin at both 4 weeks and 8 weeks (Figure 6A-F). Osteoblasts were found around the new bone in the EGFP/CS group and the BMP/CS group at 4 weeks (Figure $6 \mathrm{G}$ and $\mathrm{H}$ ).

\section{Effects of secreted BMP-2 protein on other tissues or organs in vivo}

The results from hematological and biochemical examinations of the control group and the BMP/CS treatment group in Table 2 and 3 indicate that there was no significant difference between the two groups.

Histological examination showed that the morphologies of liver, spleen, and kidney were similar between the control group and the BMP/CS treatment group, and no significant histopathological changes were observed in the tissue samples (Figure 7).

\section{Discussion}

Regeneration of bone defects is accomplished by cells, bioactive factors, and ECM, which continue to work together to regulate the proliferation, differentiation, and migration of
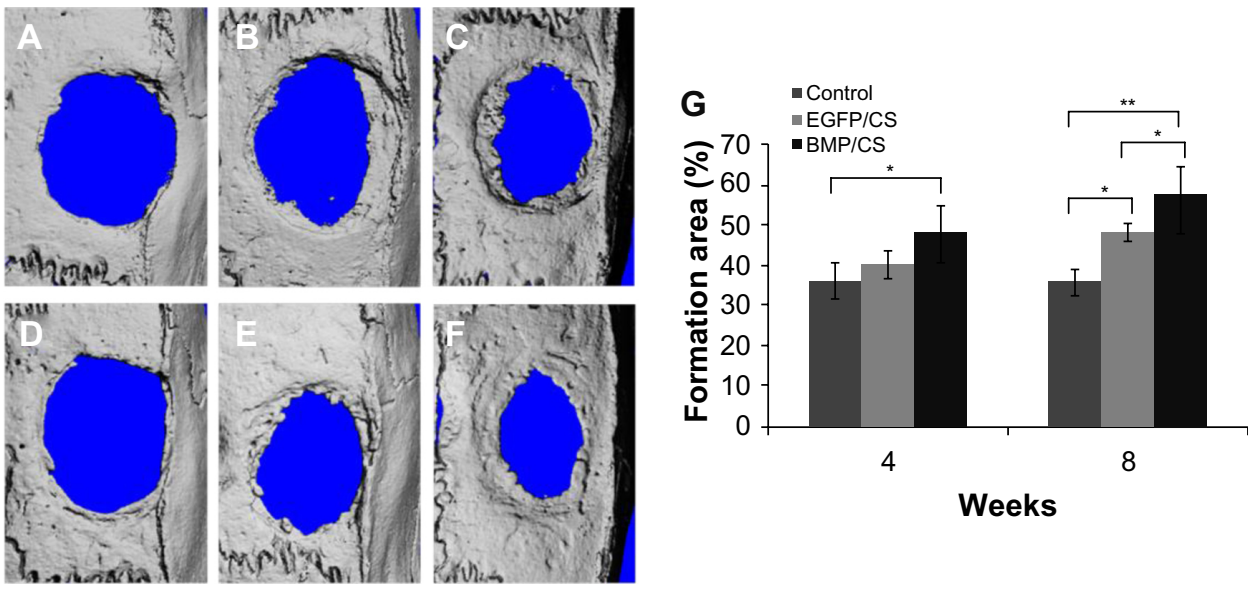

Figure 5 Microcomputed tomography images of rat cranial bone and quantification after 4 or 8 weeks post-implantation. (A) Blank control group after 4 weeks. (B) EGFP/ CS group after 4 weeks. (C) BMP/CS group after 4 weeks. (D) Blank control group after 8 weeks. (E) EGFP/CS group after 8 weeks. (F) BMP/CS group after 8 weeks. (G) Quantification of new bone area.

Notes: $* P<0.05$; $* * P<0.01$.

Abbreviations: BMP/CS, bone morphogenetic protein 2 gene-modified cell sheet; EGFP/CS, enhanced green fluorescent protein gene-modified cell sheet. 


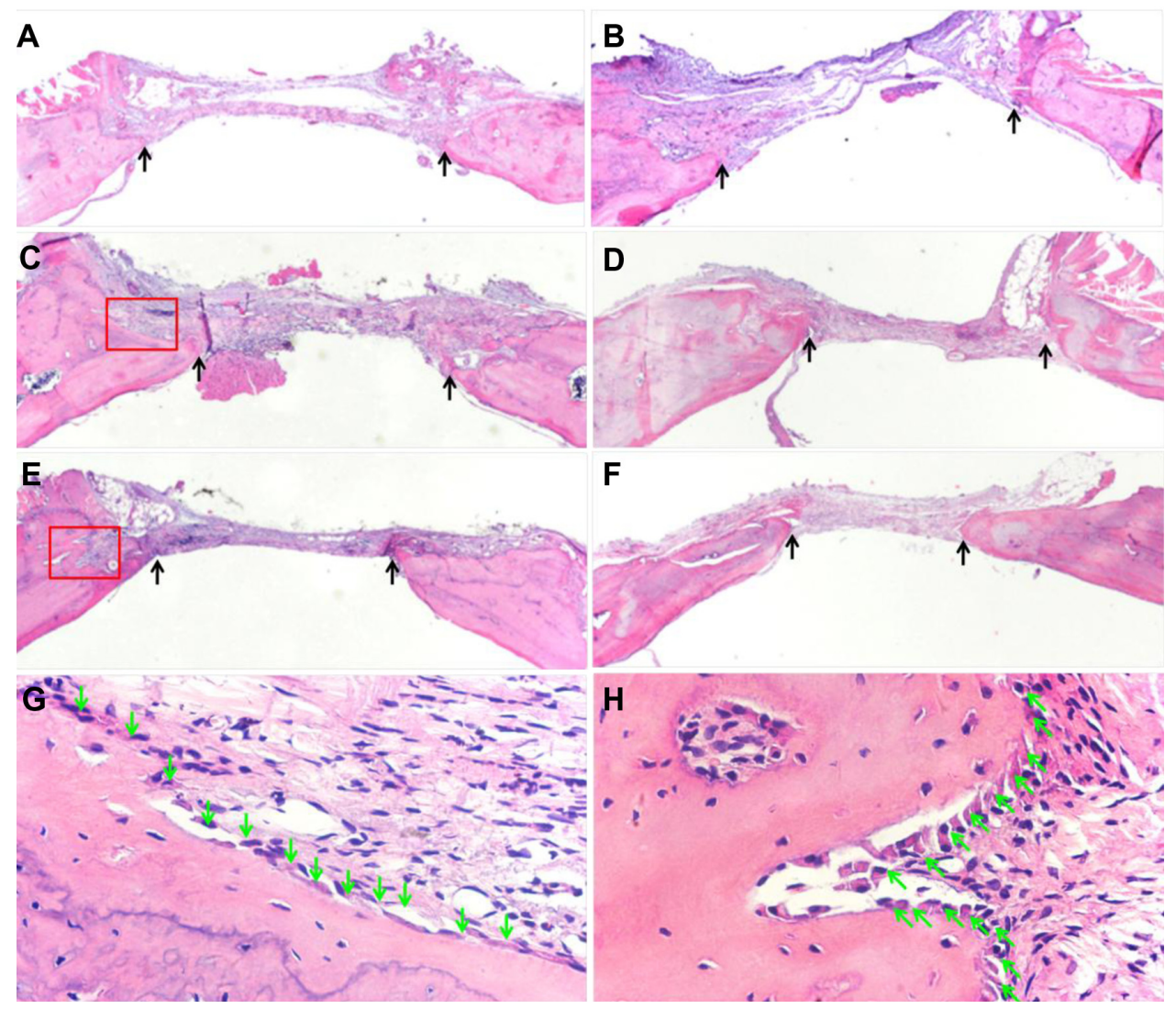

Figure 6 Hematoxylin and eosin staining of rat cranial defect after 4 or 8 weeks post-implantation. (A) Blank control group after 4 weeks $(\times 20)$. (B) Blank control group after 8 weeks $(\times 20)$. (C) EGFP/CS group after 4 weeks $(\times 20)$. (D) EGFP/CS group after 8 weeks $(\times 20)$. (E) BMP/CS group after 4 weeks $(\times 20)$. (F) BMP/CS group after 8 weeks $(\times 20)$. (G) Enlarged image of the edge of the defect in EGFP/CS group after 4 weeks $(\times 400)$. (H) Enlarged image of the edge of the defect in BMP/CS group after 4 weeks $(\times 400)$. Black arrows indicate the edge of the defect, and green arrows indicate osteoblasts.

Abbreviations: BMP/CS, bone morphogenetic protein 2 gene-modified cell sheet; EGFP/CS, enhanced green fluorescent protein gene-modified cell sheet.

osteoprogenitor cells. Recent advances in cell and molecular biology have enabled researchers in the BTE field to integrate stem cells with gene medicine. ${ }^{4,23,24}$ Herein, we applied PEI-al/pBMP-2 complexes to fabricate a BMP-2 proteinproducing cell sheet, which is an organic combination of cells, bioactive factors, and ECM.

Although the transfection efficiency of nonviral vectors is lower than that of the viral ones, these vehicles are still accepted as alternatives to the viral gene vectors, for their advantages of stability, safety, and easy modification to finely adjust their physicochemical properties. ${ }^{22,23}$
Different types of PEI are regarded as the most effective nonviral gene vectors, due to their ability to reduce the negative charge of DNA and partially condense its normally large hydrodynamic volume and the ability to escape from lysosomes. ${ }^{5,25}$ However, PEI exhibits high cytotoxicity, so many efforts have been made to modify PEI in order to decrease its cytotoxicity whilst retaining the high transfection efficiency. ${ }^{26,27}$ It is generally thought that the cytotoxicity of polycation (eg, PEI) is caused by polymer aggregation on the cell surface because of the strong electrostatic interaction with plasma membrane, which impairs

Table 2 Hematology parameters of rats treated with CS and BMP/CS at I, 3, and 7 days after surgery

\begin{tabular}{|c|c|c|c|c|c|c|}
\hline \multirow[t]{2}{*}{ Parameters } & \multicolumn{2}{|l|}{ I day } & \multicolumn{2}{|l|}{3 days } & \multicolumn{2}{|l|}{7 days } \\
\hline & CS & BMP/CS & CS & BMP/CS & CS & BMP/CS \\
\hline WBC (109/L) & $13.80 \pm 2.35$ & $16.3 \pm 6.21$ & $9.63 \pm 0.93$ & $9.73 \pm 3.95$ & $8.97 \pm 2.17$ & $10.87 \pm 2.7$ \\
\hline $\operatorname{RBC}\left(10^{12 / L}\right)$ & $7.61 \pm 0.50$ & $6.7 I \pm 0.94$ & $7.46 \pm 0.20$ & $7.03 \pm 0.45$ & $6.74 \pm 0.44$ & $6.16 \pm 0.21$ \\
\hline $\mathrm{Hb}(\mathrm{g} / \mathrm{L})$ & $136.00 \pm 16.64$ & $129.00 \pm 16.10$ & $139.67 \pm 2.52$ & $133.00 \pm 4.36$ & $123.00 \pm 4.58$ & $\mid 24.33 \pm 1.53$ \\
\hline Plt (109/L) & $888.67 \pm 162.28$ & $903.67 \pm 145.50$ & $873.00 \pm 212.64$ & $1,049.00 \pm 24.58$ & $1,162.33 \pm 11.72$ & $\mathrm{I}, \mathrm{I} 02.67 \pm 37.00$ \\
\hline
\end{tabular}

Notes: Data are expressed as mean \pm standard deviation.

Abbreviations: BMP/CS, bone morphogenetic protein 2 gene-modified cell sheet; CS, cell sheet; Hb, hemoglobin concentration; Plt, platelet; RBC, red blood cell number; WBC, white blood cell number. 
Table 3 Serum biochemical parameters of rats treated with CS and BMP/CS at I, 3, 7 days after surgery

\begin{tabular}{|c|c|c|c|c|c|c|}
\hline \multirow[t]{2}{*}{ Parameters } & \multicolumn{2}{|l|}{ I day } & \multicolumn{2}{|l|}{3 days } & \multicolumn{2}{|l|}{7 days } \\
\hline & CS & BMP/CS & CS & BMP/CS & CS & BMP/CS \\
\hline TP $(g / L)$ & $54.33 \pm 2.08$ & $54.33 \pm 1.15$ & $54.30 \pm 1.81$ & $55.40 \pm 0.98$ & $57.00 \pm 3.60$ & $55.00 \pm 2.52$ \\
\hline $\mathrm{ALT}(\mathrm{U} / \mathrm{L})$ & $68.00 \pm 21.38$ & $55.33 \pm 11.37$ & $52.40 \pm 15.57$ & $55.10 \pm 13.96$ & $65.67 \pm 18.82$ & $62.00 \pm 6.93$ \\
\hline AST (U/L) & $136.33 \pm 29.67$ & $155.00 \pm 44.93$ & $136.40 \pm 43.53$ & $158.73 \pm 29.89$ & $165.67 \pm 13.32$ & $160.67 \pm 32.47$ \\
\hline BUN (mmol/L) & $7.31 \pm 0.99$ & $6.52 \pm 0.13$ & $5.92 \pm 0.40$ & $5.85 \pm 0.49$ & $6.55 \pm 1.29$ & $6.10 \pm 1.09$ \\
\hline Cre $(\mu \mathrm{mol} / \mathrm{L})$ & $36.90 \pm 5.38$ & $38.43 \pm 4.54$ & $39.77 \pm 6.89$ & $42.40 \pm 6.55$ & $47.53 \pm 1.16$ & $46.88 \pm 3.95$ \\
\hline
\end{tabular}

Notes: Data are expressed as mean \pm standard deviation.

Abbreviations: ALT, alanine aminotransferase; AST, aspartate aminotransferase; BMP/CS, bone morphogenetic protein 2 gene-modified cell sheet; BUN, blood urea nitrogen; Cre, creatinine; CS, cell sheet; TP, total protein.

the cell membrane functions. ${ }^{28}$ Alginate is an anionic polysaccharide with good biosafety and biodegradability and has been widely used in gene and drug delivery. ${ }^{29,30}$ In this study, PEI-al nanocomposites were synthesized by electrostatic interaction between cationic polymer PEI and anionic polymer alginate, and blending polyanionic alginate with PEI successfully shielded the excess positive charge on PEI and then reduced its toxicity (Figure 3B). Furthermore, this method of synthesizing PEI-al nanocomposites is very simple and easy to carry out.

The transduction of viral vectors to BMSCs has been achieved, and it has relatively high transduction efficiency.
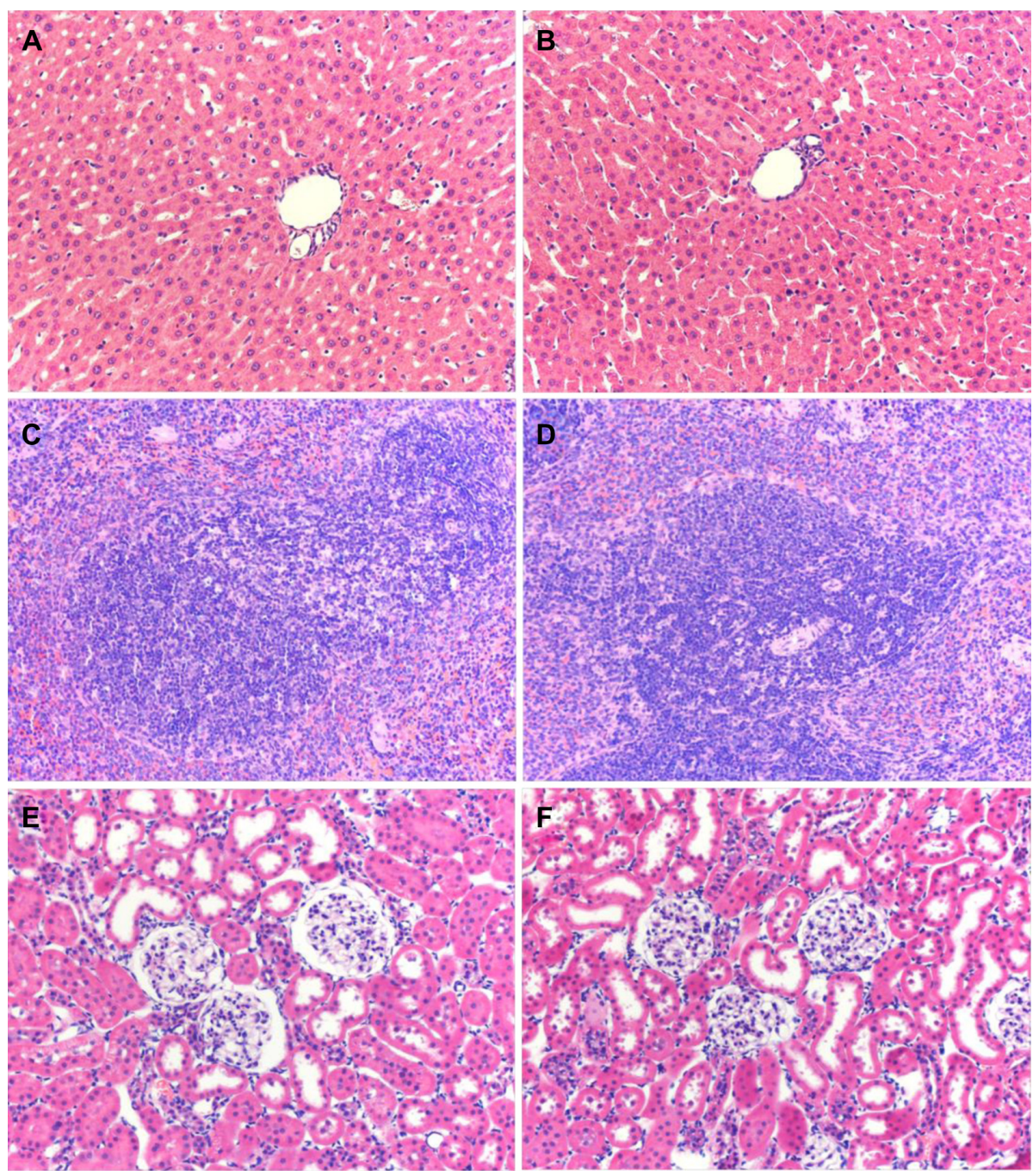

Figure 7 Hematoxylin and eosin staining of liver, spleen, and kidney from rats treated with CS and BMP/CS at 7 days after surgery. (A) Liver of CS group $(\times 200)$. (B) Liver of BMP/CS group $(\times 200)$. (C) Spleen of CS group $(\times 200)$. (D) Spleen of BMP/CS group $(\times 200)$. (E) Kidney of CS group $(\times 200)$. $(\mathbf{F})$ Kidney of BMP/CS group $(\times 200)$. Abbreviations: BMP/CS, bone morphogenetic protein 2 gene-modified cell sheet; $C S$, cell sheet. 
However, the nonviral vectors, cationic polymers, and lipids are found to be ineffective for delivering plasmid DNA into BMSCs, although they have been used to deliver genes to other cell types. ${ }^{4,31,32}$ In this study, the transfection efficiency of PEI-al nanocomposites was evaluated on BMSCs. PEI-al nanocomposites are quite effective gene carriers, which is demonstrated by the flow cytometry results, with the maximum transfection efficiency of PEI-al 2.5-fold higher than that of PEI on BMSCs (Figure 3A).

Cell sheet has emerged as a mesenchymal stem cells (MSCs) delivery system for bone defect healing. ${ }^{10,11,32}$ In this study, Vc was added to create cell sheet, because of its properties of increasing cell proliferation and ECM biosynthesis. ${ }^{12}$ Liu et al ${ }^{33}$ also found that BMSC sheet could evidently enhance osteogenic differentiation compared with BMSCs, which because of the cell sheet enriches ECM and plays an important role in regulating the cell differentiation.

In addition, to further increase osteogenic potential of the cell sheet, BMP-2 gene was used to transfect BMSCs during the cell sheet formation period. BMP-2 has the capability of inducing osteogenic differentiation of mesenchymal cells, ${ }^{34,35}$ and $B M P-2$ gene transfection is also proven to be an effective strategy to promote stem cell osteogenic differentiation and mineralized tissue formation. ${ }^{4}$ However, the new bone formation is different between rhBMP-2 application and cell-mediated BMP-2 secretion by gene transfer. Previous studies show that the bone defect receiving only rhBMP-2 protein cannot form a continual structure as per the original bone, in contrast to the bone formation induced by $B M P-2$ gene transfer. The explanation might be that the BMP-2-producing BMSCs are used as carriers and BMP-2 protein is released continuously. ${ }^{4,24,36,37}$ In our study, the release of BMP-2 protein from the transfected BMSCs was also observed, indicating that BMP-2 was sustainably released for at least 14 days (Figure 3C). Previous studies demonstrate that the application of BMP-2 in vivo may cause systemic toxicity. ${ }^{4,6,23}$ On the other hand, protein delivery via genemodified cells could reduce the risk because the protein is mainly released locally., ${ }^{4,6}$ Our current study showed that there was no toxic effect from blood samples and tissue samples of liver, spleen, and kidney from the BMP2-treated group (Table 2 and 3, Figure 7). These results indicate that it is a safe and effective method to deliver BMP-2 protein using a gene-modified cell sheet.

The secreted BMP-2 protein plays a role in inducing bone formation via autocrine and paracrine pathways. Due to the limitation of relatively low transfection efficiency in BMSCs, only parts of the cells express BMP-2 protein. These cells can differentiate into osteoblastic lineage via the autocrine pathway, and further induce the differentiation of neighboring cells to osteoprogenitor cells via the paracrine pathway. ${ }^{4,18}$ In our study, the result of the qPCR showed that the secreted BMP-2 protein had the capability of increasing osteogenic gene expressions, which are the main markers of BMSCs differentiating to preosteoblast or mature osteoblast (Figure 4). ${ }^{38}$ This result indicates that during the period of the BMSC sheet formation, the BMSCs differentiated to osteoblastic lineage in vitro. Previous studies also show that the secreted BMP-2 protein influences not only the unmodified BMSCs but also the neighboring periosteal cells. ${ }^{4,18}$ Figure $6 \mathrm{G}$ and $\mathrm{H}$ show that at 4 weeks osteoblasts were observed around the new bone. The osteoblasts in the BMP/CS groups were cuboidal shape, indicating that these cells were actively synthesizing osteoid. These results demonstrate how the genetically engineered cell sheet could sustainably release BMP-2 protein and potentially be utilized clinically to repair bone defects.

\section{Conclusion}

Our study demonstrated that PEI-al nanocomposites can efficiently transfect BMSCs and that BMP-2 gene-engineered cell sheet can successfully induce osteogenic differentiation of BMSCs in vitro and enhance bone formation at the bone defect area in vivo. Although this study targets the use of $B M P$-2 gene-modified cell sheet, future studies will determine whether a multilayer cell sheet constructed by $B M P-2$ gene and other genes might have better capability to promote tissue regeneration.

\section{Acknowledgment}

This work was supported by the National Natural Science Foundation of China (81320108011, 81271111, 30830108), the Research Fund for the Doctoral Program of Higher Education of China (233200801830063, 20120061130010), and the Science Technology Development Program of Jilin Province (2011 I 051).

\section{Disclosure}

The authors report no conflicts of interest in this work.

\section{References}

1. Hernández A, Sánchez E, Soriano I, Reyes R, Delgado A, Évora C. Material-related effects of BMP-2 delivery systems on bone regeneration. Acta Biomater. 2012;8(2):781-791.

2. Neovius E, Engstrand T. Craniofacial reconstruction with bone and biomaterials: review over the last 11 years. J Plast Reconstr Aesthet Surg. 2010;63(10):1615-1623. 
3. Bostrom MP, Seigerman DA. The clinical use of allografts, demineralized bone matrices, synthetic bone graft substitutes and osteoinductive growthfactors: a survey study. HSS J. 2005;1(1):9-18.

4. Park J, Ries J, Gelse K, et al. Bone regeneration in critical size defects by cell-mediated BMP-2 gene transfer: a comparison of adenoviral vectors and liposomes. Gene Ther. 2003;10(13):1089-1098.

5. Qiao C, Zhang K, Jin H, et al. Using poly(lactic-co-glycolic acid) microspheres to encapsulate plasmid of bone morphogenetic protein 2/polyethylenimine nanoparticles to promote bone formation in vitro and in vivo. Int J Nanomedicine. 2013;8:2985-2995.

6. Fischer J, Kolk A, Wolfart S, et al. Future of local bone regeneration: protein versus gene therapy. J Craniomaxillofac Surg. 2011;39(1): $54-64$.

7. Porter JR, Ruckh TT, Popat KC. Bone tissue engineering: a review in bone biomimetics and drug delivery strategies. Biotechnol Prog. 2009; 25(6):1539-1560.

8. Okano T, Yamada N, Sakai H, Sakurai Y. A novel recovery system for cultured cells using plasma-treated polystyrene dishes grafted with poly (N-isopropylacrylamide). J Biomed Mater Res. 1993;27(10): 1243-1251.

9. Okano T, Yamada N, Okuhara M, Sakai H, Sakurai Y. Mechanism of cell detachment from temperature-modulated, hydrophilic-hydrophobic polymer surfaces. Biomaterials. 1995;16(4);297-303.

10. Nakamura A, Akahane M, Shigematsu H, et al. Cell sheet transplantation of cultured mesenchymal stem cells enhances bone formation in a rat nonunion model. Bone. 2010;46(2):418-424.

11. Ma D, Ren L, Chen F, et al. Reconstruction of rabbit critical-size calvarial defects using autologous bone marrow stromal cell sheets. Ann Plast Surg. 2010;65(2):259-265.

12. Wei F, Qu C, Song T, et al. Vitamin C treatment promotes mesenchymal stem cell sheet formation and tissue regeneration by elevating telomerase activity. J Cell Physiol. 2012;227(9):3216-3224.

13. Urist M. Bone: formation by autoinduction. Science. 1965;150(3698): 893-899.

14. Luvizuto ER, Tang S, Zanoni G, et al. The effect of BMP-2 on the osteoconductive properties of b-tricalcium phosphate in rat calvaria defects. Biomaterials. 2011;32(15):3855-3861.

15. Lee JW, Kang KS, Lee SH, Kim JY, Lee BK, Cho DW. Bone regeneration using a microstereolithography-produced customized poly (propylene fumarate)/diethyl fumarate photopolymer 3D scaffold incorporating BMP-2 loaded PLGA microspheres. Biomaterials. 2011; 32(3):744-752.

16. Wang EA, Rosen V, D'Alessandro JS, et al. Recombinant human bone morphogenetic protein induces bone formation. Proc Natl Acad Sci. 1990;87(6):2220-2224.

17. Nauth A, Ristevski B, Li R, Schemitsch EH. Growth factors and bone regeneration: how much bone can we expect? Injury. 2011;42(6): 574-579.

18. Riew KD, Wright NM, Cheng S, Avioli LV, Lou J. Induction of bone formation using a recombinant adenoviral vector carrying the human BMP-2 gene in a rabbit spinal fusion model. Calcif Tissue Int. 1998; 63(4):357-360.

19. Sellers RS, Zhang R, Glasson SS, et al. Repair of articular cartilage defects one year after treatment with recombinant human bone morphogenetic protein-2 (rhBMP-2). J Bone Joint Surg Am. 2000;82(2): $151-160$.
20. Nie H, Ho ML, Wang CK, Wang CH, Fu YC. BMP-2 plasmid loaded PLGA/HAp composite scaffolds for treatment of bone defects in nude mice. Biomaterials. 2009;30(5):892-901.

21. Crystal RG. Transfer of genes to humans: early lessons and obstacles to success. Science. 1995;270(5235):404-410.

22. Patnaik S, Aggarwal A, Nimesh S, et al. PEI-alginate nanocomposites as efficient in vitro gene transfection agents. J Control Release. 2006;114(3):398-409.

23. Kimelman Bleich N, Kallai I, Lieberman JR, Schwarz EM, Pelled G, Gazit D. Gene therapy approaches to regenerating bone. Adv Drug Deliv Rev. 2012;64(12):1320-1330.

24. Evans C. Gene therapy for the regeneration of bone. Injury. 2011;42(6): 599-640.

25. Choosakoonkriang S, Lobo BA, Koe GS, Koe JG, Middaugh CR. Biophysical characterization of PEI/DNA complexes. J Pharm Sci. 2003;92(8):1710-1722.

26. Zhao X, Li Z, Pan H, et al. Enhanced gene delivery by chitosan-disulfideconjugated LMW-PEI for facilitating osteogenic differentiation. Acta Biomater. 2013;9(5):6694-6703.

27. Huang FW, Wang HY, Li C, et al. PEGylated PEI-based biodegradable polymers as non-viral gene vectors. Acta Biomater. 2010;6(11): 4285-4295.

28. Yu JH, Quan JS, Huang J, et al. $\alpha, \beta$-Poly(L-aspartate-graft-PEI): A pseudo-branched PEI as a gene carrier with low toxicity and high transfection efficiency. Acta Biomater. 2009;5(7):2485-2494.

29. Poojari R, Srivastava R. Composite alginate microspheres as the nextgeneration egg-box carriers for biomacromolecules delivery. Expert Opin Drug Deliv. 2013;10(8):1061-1076.

30. Nitta SK, Numata K. Biopolymer-based nanoparticles for drug/gene delivery and tissue engineering. Int J Mol Sci. 2013;14(1):1629-1654.

31. Clements BA, Incani V, Kucharski C, Lavasanifar A, Ritchie B, Uluda $\breve{~ H . ~}$ A comparative evaluation of poly-L-lysine-palmitic acid and Lipofectamine ${ }^{\mathrm{TM}} 2000$ for plasmid delivery to bone marrow stromal cells. Biomaterials. 2007;28(31):4693-4704.

32. Akiyama H, Ito A, Kawabe Y, Kamihira M. Genetically engineered angiogenic cell sheets using magnetic force-based gene delivery and tissue fabrication techniques. Biomaterials. 2010;31(6):1251-1259.

33. Liu Y, Ming L, Luo H, et al. Integration of a calcined bovine bone and BMSC-sheet 3D scaffold and the promotion of bone regeneration in large defects. Biomaterials. 2013;34(38):9998-10006.

34. Huang W, Carlsen B, Wulur I, et al. BMP-2 exerts differential effects on differentiation of rabbit bone marrow stromal cells grown in twodimensional and three-dimensional systems and is required for in vitro bone formation in a PLGA scaffold. Exp Cell Res. 2004;299(2):325-334.

35. Rosen V. BMP2 signaling in bone development and repair. Cytokine Growth Factor Rev. 2009;20(5-6):475-480.

36. Lieberman JR, Daluiski A, Stevenson S, et al. The effect of regional gene therapy with bone morphogenetic protein-2-producing bone-marrow cells on the repair of segmental femoral defects in rats. $J$ Bone Joint Surg Am. 1999;81(7):905-917.

37. Gazit D, Turgeman G, Kelley P, et al. Engineered pluripotent mesenchymal cells integrate and differentiate in regenerating bone: a novel cell-mediated gene therapy. J Gene Med. 1999;1(2):121-133.

38. Ryoo HM, Lee MH, Kim YJ. Critical molecular switches involved in BMP-2-induced osteogenic differentiation of mesenchymal cells. Gene. 2006;366(1):51-57.
International Journal of Nanomedicine

\section{Publish your work in this journal}

The International Journal of Nanomedicine is an international, peerreviewed journal focusing on the application of nanotechnology in diagnostics, therapeutics, and drug delivery systems throughout the biomedical field. This journal is indexed on PubMed Central, MedLine, CAS, SciSearch ${ }^{\circledR}$, Current Contents ${ }^{\circledR} /$ Clinical Medicine,

\section{Dovepress}

Journal Citation Reports/Science Edition, EMBase, Scopus and the Elsevier Bibliographic databases. The manuscript management system is completely online and includes a very quick and fair peer-review system, which is all easy to use. Visit http://www.dovepress.com/ testimonials.php to read real quotes from published authors. 